\title{
Molecular clocks, biogeography and species diversity in Herichthys with evaluation of the role of Punta del Morro as a vicariant brake along the Mexican Transition Zone in the context of local and global time frame of cichlid diversification
}

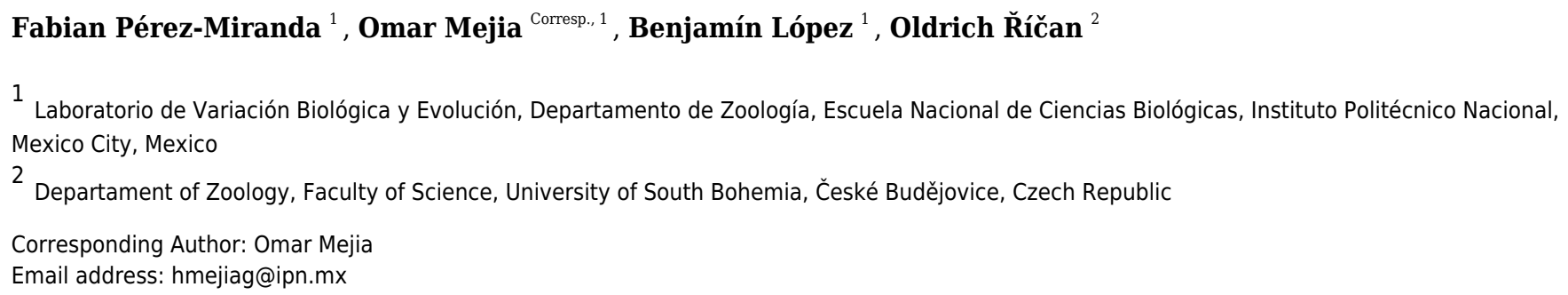

Using molecular dated phylogenies and biogeographic reconstructions, the species diversity, biogeography and time frame of evolution of the genus Herichthys were evaluated. Particularly, we test the role of Punta del Morro (PdM) as a vicariant brake along the Mexican Transition Zone in the context of local and global time frame of cichlid diversification using several sets of calibrations. Species diversity in Herichthys is complex and the here employed dating methods suggest young age and rapid divergence for many species while species delimitation methods did not resolve these young species including both sympatric species pairs. Based on our molecular clock dating analyses Herichthys has colonized its present distribution area significantly prior to the suggested vicariance by PdM (10 -17.1 Ma vs. 5 to 7.5 Ma). The PdM constraint is in conflict with all other paleogeographic and fossil constraints including novel ones introduced in this study that are however congruent among each other. Our study demonstrates that any cichlid datings significantly older or younger than the bounds presented by our analyses and discussion have to taken as highly questionable from the point of view of Middle American paleogeography and cichlid biogeography unless we allow the option that cichlid biogeography is completely independent from ecological and geological constraints. 
1 Molecular clocks, biogeography and species diversity in Herichthys with evaluation of the 2 role of Punta del Morro as a vicariant brake along the Mexican Transition Zone in the 3 context of local and global time frame of cichlid diversification

4

5 Fabian Pérez-Miranda ${ }^{1}$, Omar Mejía*1 ${ }^{*}$, Benjamín López ${ }^{1}$ and Oldřich Ř́ćan ${ }^{2}$

6

$7 \quad{ }^{1}$ Laboratorio de Variación Biológica y Evolución, Departamento de Zoología, Escuela Nacional

8 de Ciencias Biológicas, Instituto Politécnico Nacional, México City, México

9

10

11 Czech Republic

12

13 Corresponding author:

14 Omar Mejía

15 Email adress: hmejiag@ipn.mx; homarmejia@hotmail.com.

16

17

18

19

20

21

22

23

24

25

26

27

28

29 


\section{Abstract}

31 Using molecular dated phylogenies and biogeographic reconstructions, the species diversity,

32 biogeography and time frame of evolution of the genus Herichthys were evaluated. Particularly,

33 we test the role of Punta del Morro (PdM) as a vicariant brake along the Mexican Transition

34 Zone in the context of local and global time frame of cichlid diversification using several sets of

35 calibrations. Species diversity in Herichthys is complex and the here employed dating methods

36 suggest young age and rapid divergence for many species while species delimitation methods did

37 not resolve these young species including both sympatric species pairs. Based on our molecular

38 clock dating analyses Herichthys has colonized its present distribution area significantly prior to

39 the suggested vicariance by PdM (10-17.1 Ma vs. 5 to $7.5 \mathrm{Ma})$. The PdM constraint is in

40 conflict with all other paleogeographic and fossil constraints including novel ones introduced in

41 this study that are however congruent among each other. Our study demonstrates that any cichlid

42 datings significantly older or younger than the bounds presented by our analyses and discussion

43 have to taken as highly questionable from the point of view of Middle American paleogeography

44 and cichlid biogeography unless we allow the option that cichlid biogeography is completely

45 independent from ecological and geological constraints.

46

47

48

49

50

51

52

53

54

55 


\section{Introduction}

58 Myers (1966), in his seminal work, concluded that the fish fauna of Central America is

59 dominated by secondary freshwater fishes (mainly Poeciliidae and Cichlidae) and that the fauna

60 was established by colonization during the Early Tertiary, while primary fishes did not arrive

61 until a connection was established with South America in the Late Tertiary. Since Myers, several

62 studies have tested and refined his hypothesis. Rosen (1975) put forth that the first connection for

63 freshwater fishes between Middle America and South America might have started already in the

64 late Cretaceous. However, for both the poeciliid and cichlid families, we still do not know their

65 precise dates of colonization because the numerous studies dedicated to the topic have supported

66 strongly different timeframes for their colonization. All studies agree that unlike the multiple

67 widely spaced colonizations by the poeciliids, cichlids colonized Middle America during a single

68 timeframe (Hrbek et al. 2007; Tagliacollo et al. 2017; Matamoros et al, 2015). The first studies

69 of cichlids used a $1 \%$ to $2 \%$ substitution rate of mitochondrial DNA, positing that colonization

70 occurred between 11.3 to 13.3 Ma (Martin and Bermingam 1998) and 14 to $18 \mathrm{Ma}$ (based on a

71 1\% substitution rate; Concheiro Pérez et al. 2007). Using the Punta del Morro (PdM) as a

72 calibration point (7.5 Ma), Hulsey et al. (2004) suggested a similar age of 16.2 Ma for

73 colonization. However, using two geological events, the separation of Cuba and Hispaniola (23

74 to $24 \mathrm{Ma}$ ) and that of the Orinoco and Magdalena basins (10.1-11.8 Ma), Concheiro Pérez et al.

75 (2007) suggested an older age of 20 to $24 \mathrm{Ma}$ for colonization. In the most detailed study of the

76 cichlids so far, Říčan et al. (2013) employed as calibration points the same events as Concheiro

77 Pérez et al. (2007) plus the minimum age of the fossil, Plesioheros chauliodus (39.9-48.6 Ma),

78 and concluded that the cichlid fishes colonized simultaneously Middle America and the Greater

79 Antilles much earlier, between 32 and $24 \mathrm{Ma}$ in the Oligocene. Tagliacollo et al. (2017) using a

80 different set of fossil calibrations (plus a questionable minimum age of cichlids) reconstructed an

81 even earlier colonization of Middle America and the Greater Antilles by the cichlids during the

82 Paleocene-Eocene (ca. 45-50 Ma). Additionally, there are several other studies that include some

83 Middle American cichlids (but are not dedicated to the Middle American and Caribbean cichlids)

84 in dated phylogenies and these also provided a wide range of dates for the colonization. For

85 example, the dated phylogeny of Musilová et al. (2015) suggested a colonization date of Middle

86 America between 32 and $26 \mathrm{Ma}$, while the largest study dedicated to cichlid dating of Matschiner 
87 et al. (2017) suggested a colonization date between 44 and 31 Ma. Finally, the third group of

88 studies used for calibration the assumed cichlid vicariance of western Gondwana (South 89 America-Africa) and place the colonization around 55 Ma (e.g. López-Fernández et al. 2013).

90 Both the dedicated and non-dedicated calibrated phylogenies have thus provided a wide range of 91 dates for the colonization of Middle America and the Antilles ranging from $16 \mathrm{Ma}$ (Hulsey et al. 92 (2004), between 24 and 32 Ma (Concheiro Pérez et al. 2007; Říčan et al. 2013; Musilová et al. 93 2015), around 44 to $45 \mathrm{Ma}$ (Matschiner et al. 2017; Tagliacollo et al. 2017) and up to $55 \mathrm{Ma}$ 94 (e.g., López-Fernández et al. 2013;). The 24-32 Ma group of studies is compatible with the 95 GAARlandia landbridge hypothesis of land connection between South America, the Greater 96 Antilles and Middle America (Iturralde-Vinent and MacPhee 1999) with only minor sea 97 crossings, while the studies with the older dates imply or even advocate almost complete 98 transoceanic dispersal, additionally complicated by the absence of terrestrial habitats in the 99 Greater Antilles between the end of the Cretaceous and Eocene-Oligocene (ca. 66 and $37 \mathrm{Ma}$; 100 Iturralde-Vinent and MacPhee 1999; MacPhee and Iturralde-Vinent 2005). Southern Central 101 America, including Eastern Panama, is unequivocally reconstructed in all studies as having been 102 colonized from Northern Middle America starting in the Early-Middle Miocene and a limited 103 colonization of Eastern Panamá coincided with the first wave of colonization of this area by 104 primary freshwater fishes from South America (Bermingham and Martin 1998).

105 The available studies have thus given a very wide window of reconstructed dates of 106 colonization of Middle America by the Cichlidae. Most of the debate in dating of cichlid 107 phylogenies revolves around the topic of colonization of South America from Africa (review in 108 Matschiner, 2019), a very ancient and controversial event. We believe that a better way by which 109 to make progress in this debate is to concentrate on and better constrain the dating by focusing 110 on the study of more regional, recent and hence tractable biogeography of cichlid fishes, in the 111 case of this study within Middle America. The phylogeny of Middle American cichlids is now 112 completely known based on complete species-level sampling and also genomic phylogenies 113 (Říčan et al. 2013, 2016; Ilves et al. 2018). The testing of regional biogeographic patterns and 114 events is thus straightforward using these datasets. Thus far, only one calibration point derived 115 from Middle American biogeography was employed in the dating of cichlid biogeography, and 116 that is the PdM (Hulsey et al. 2004, 2010). The PdM is a lava flow from the Transmexican 117 Volcanic Belt that extends almost to the coastal line in the Mexican state of Veracruz, found at 
118 the northern border of the Neotropical zone where it terminates along a transition zone in 119 Mexico.

120 The PdM has been demonstrated to act as an effective barrier or filter within this 121 transition zone for freshwater species. The fish fauna drastically changes from being $75 \%$ of

122 Nearctic origin north of PdM to 95\% of Neotropical origin south of PdM (Obregón-Barboza et 123 al. 1994; Miller et al. 2005). The importance of the PdM as a biogeographic break has been 124 recognized not only for aquatic species, but also reptiles and mammals (Pérez-Higareda and 125 Navarro 1980; Mulcahy and Mendelson 2000; Savage and Wake 2001).

126 While the biogeographic break at the PdM is well-demonstrated, the historical influence 127 of this postulated barrier is not understood. Most studies of freshwater fishes in this area assumed 128 that the PdM acted as a vicariant event (in cichlids, characids and poecilids; Hulsey et al, 2004; 129 Mateos 2005; Ornelas-García et al. 2008; Agorreta et al. 2013; Culumber and Tobler 2016; 130 Palacios et al. 2016). However, the divergence time estimates in the aforementioned works 131 (which range between 4.4 to $6 \mathrm{Ma}$ ) contrast strongly with the at least $14 \mathrm{Ma}$ (and significantly 132 more in several of the studies) estimated in other studies of cichlids, thereby clearly predating the

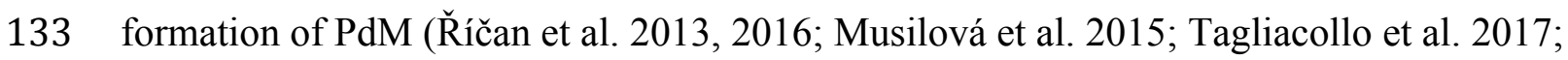
134 Matschiner et al. 2017).

135 Huidobro et al. (2006) analyzed the distribution patterns of several groups of aquatic taxa 136 distributed below $1000 \mathrm{~m}$ altitude (crustaceans, angiosperms and fishes) and found three 137 biogeographic tracks. One of them included the transition zone with the panbiogeographic track 138 being interrupted at the PdM. Their study suggested that the track is coupled with eustatic sea 139 changes that occurred during the Miocene, which is in agreement with the older dating of fish

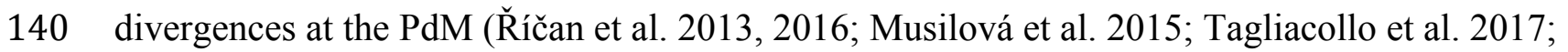
141 Matschiner et al. 2017).

142 Among the cichlids only one genus, Herichthys, is found north of the PdM. Its 143 phylogenetic position among the cichlids is now well-understood (Říčan et al. 2013, 2016), but 144 the reasons for it being the only genus north of the PdM are not agreed upon, similarly as the 145 controversial cases of South American colonization and of colonization of Middle America. One 146 group of studies maintains that this distribution is a result of vicariance caused by the formation 147 of the PdM (Hulsey et al, 2004) as had been suggested for other fish groups (Mateos 2005; 148 Ornelas-García et al. 2008;;Agorreta et al. 2013; Culumber and Tobler, 2016; Palacios et al. 
149 2016). However, other studies put forth that colonization took place during the Miocene (乔ían 150 et al. 2013) and hence significantly predated the origin of the PdM (Říčan et al. 2013, 2016;

151 Musilová et al. 2015; Tagliacollo et al. 2017; Matschiner et al., 2017). Herichthys is thus the 152 only cichlid group able to shed light on cichlid divergence across the PdM. The clarification of 153 this and other biogeographic events within Middle America in turn has the potential to narrow 154 the timeframe of cichlid colonization of Middle America and of South America.

155 Herichthys is a unique genus among Middle American cichlids because it is the only cichlid 156 genus in Middle America not found in sympatry with other genera and it is the northernmost 157 cichlid genus on the Atlantic slope of the Americas (Říčan et al. 2016) as well as the only one 158 present north of the Mexican Transition Zone. As a consequence of its isolation, Herichthys is 159 the most diverse genus in terms of its ecomorphology among the Middle American cichlids

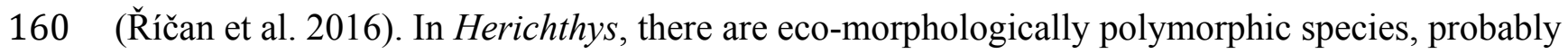
161 in early stages of speciation, and also sympatric and syntopic sister species that together with the 162 nature of their isolation and ecomorphological divergence suggest sympatric speciation (Říčan et 163 al. 2016; Pérez-Miranda et al. 2018). A large proportion of the diversity in Herichthys is 164 therefore potentially the result of ecological opportunity afforded to the genus by the absence of 165 other sympatric cichlid genera (Seehausen 2015; Říčan et al. 2016; Burress et al. 2018; Piálek et 166 al. 2018a,b).

167 Herichthys is thus of great promise as a model for the understanding of several general 168 aspects of cichlid diversification in Middle America. Indeed, one of its species (H. minckleyi) has 169 already become a model species owing to the presence of three distinct ecomorphs within this 170 species. A similar degree of intraspecific diversity is also found in H. bartoni, where it however 171 still needs to attract attention of the research community. Herichthys holds great potential to 172 become a similarly useful model of diversification in North America, just as afforded by the 173 genus Amphilophus in Central America, because of the many parallels between the two genera, 174 most importantly diversification in both riverine and lacustrine habitats, sympatric ecological 175 divergence, incipient speciation, and parallel evolution of novel traits (Barluenga et al. 2006; 176 Elmer et al. 2010 a,b; Elmer et al. 2014).

177 While the phylogenetic position of Herichthys within Middle American cichlids is well178 established (Ǩíčan et al. 2016), its species diversity is complicated and remains contested 179 (reviewed in Pérez-Miranda et al. 2018). Pérez-Miranda et al. (2018) have evaluated the 
180 usefulness of several nDNA and mtDNA markers and concluded that the best resolution of both

181 phylogenetic relationships and species-diversity issues was achieved by the nDNA ddRAD and

182 mtDNA cytb datasets among those currently available. Based on the available data that also

183 included morphological diagnosability of the species, Pérez-Miranda et al. (2018) have

184 concluded that Herichthys includes 11 species (one species has not been evaluated, H. molango, 185 and several recently described species were placed in synonymy).

186 In this study, we first focus on the species diversity analyses within Herichthys using an 187 extended sampling of the cytb marker (including H. molango) in order to clarify the diversity 188 within Herichthys. We then use biogeographical analyses and dated phylogenies of Herichthys

189 calibrated by various constraints to evaluate the PdM biogeographical break within the wider 190 Middle American and global cichlid diversification context. Middle America is particularly 191 useful for constraining cichlid datings due to its complex history and biogeography as an 192 evolving bridge between two continents. Our approach should thus beside the clarification of 193 Herichthys dating and biogeography serve to narrow the time window of cichlid colonization of 194 Middle America, in particular, and of the Neotropics in general.

\section{Material and Methods}

196 Species identification, molecular dataset and laboratory protocols

197 All specimens analyzed in this study were euthanized according with the procedure described in 198 the Mexican law NOM-033-SAG/ZOO-2014. We combine morphological species determination 199 of Herichthys species with post-hoc species delimitation using the molecular mtDNA 200 cytochrome b (cytb) marker. Specimens were identified to species with the use of original 201 descriptions, identification keys, and comparative material. Our sampling for molecular analyses 202 includes all described species of Herichthys including H. molango that has not been previously 203 evaluated. The dataset is based on that of Říčan et al. (2016) and Pérez-Miranda et al. (2018) 204 with the inclusion of many newly generated sequences (see supplemental Table S1). The dataset 205 includes the complete cytb marker (1137 bp) with 164 specimens (i.e., 141 haplotypes) from 62 206 localities (Fig. 1; compared to 99 specimens from 32 localities in Říčan et al. 2016 and Pérez-

207 Miranda et al. 2018). The dataset is anchored by 13 additional species, i.e. Hypselecara 208 coryphaenoides, Symphysodon aequifasciata, Mesonauta festivus, Heros sp., Uaru 209 amphiacanthoides, Nandopsis tetracanthus, Nandopsis haitiensis, Caquetaia sp. cf kraussi, 210 Caquetaia spectabilis,-Vieja maculicauda, Vieja melanura, Thorichthys helleri and Thorichthys 
211 pasionis which are used to provide an evenly spaced set of successive outgroups some of which

212 are used for the various molecular clock dating analyses.

213 Genomic DNA was extracted from ethanol-preserved muscle tissue using a salt extraction

214 protocol (Aljanabi and Martínez 1997). The complete sequence of mitochondrial cytochrome b

215 was amplified using the primers, CYTBF (5' AATGACTTGAAAAACCACCGTTG3') and

216 CYTBR (5'GTCTTGTAAACCGGACGCCGAA 3'), designed for this study. PCR

217 amplifications were performed in a thermocycler (Geneamp PCR System 9700, California,

218 USA) with 25-ml reactions containing 1X PCR buffer, $3.0 \mathrm{mM} \mathrm{MgCl} 2,200 \mu \mathrm{M}$ of each dNTPs,

$2190.25 \mu \mathrm{M}$ of each primer, $40 \mathrm{ng}$ of total DNA, and $1 \mathrm{U}$ of Taq DNA polymerase (Invitrogen).

220 PCR conditions were as follows: $95^{\circ} \mathrm{C}$ for $5 \mathrm{~min}$ followed by 35 cycles of $94{ }^{\circ} \mathrm{C}$ for $60 \mathrm{~s}$; an

221 annealing temperature of $60{ }^{\circ} \mathrm{C}$ for $70 \mathrm{~s} ; 72{ }^{\circ} \mathrm{C}$ for $60 \mathrm{~s}$; and a final extension at $72{ }^{\circ} \mathrm{C}$ for $5 \mathrm{~min}$.

222 PCR products were purified with the StrataPrep PCR purification kit (Agilent Technologies,

223 California, USA) and sequenced at Laboratorio de Servicios Genómicos Langebio-Cinvestav

224 Irapuato, Mexico. DNA sequences were edited manually and aligned with Seaview v. 3.2

225 (Galtier et al. 1996). Nucleotide coding sequences were also translated into protein sequences to

226 check for possible stop codons or other ambiguities. Sequence data have been deposited in

227 GenBank under the following accession numbers (MK481080-MK481126). Prior to

228 phylogenetic analyses, sequences were collapsed to haplotypes in FaBox (Villesen 2007).

229 Phylogenetic methods and molecular clock

230 Phylogenetic inference was performed using neighbor joining and maximum parsimony (MP)

231 analysis in PAUP* 4b.10 (Swofford 2003) in the first exploratory phase of building the dataset.

232 These analyses were followed by maximum likelihood RaxML analysis with data partition into

$2331^{\text {st }+2^{\text {nd }}}$ vs. $3^{\text {rd. }}$ position and with a GTR + gamma + I model and bootstrapping as well as a

234 BEAST (Suchard et al. 2018) analysis with a relaxed molecular clock model with lognormal

235 distribution of rates and a coalescent model with constant size tree prior. For BEAST analysis

236 four independent runs of 30 millions and sampling each 10000 generations were performed.

237 After it, runs were verified for convergence with Tracer v.1.10.1 (Rambaut et al. 2018) and the

238 trees of the four well-converged runs were combined in LogCombiner v.1.10.1 with a burn-in of

$23910 \%$ and a consensus tree was obtained with TreeAnnotator v.1.8.4, above mentioned analysis

240 well performed in the Cipres server (https://www.phylo.org/). 
For divergence time estimation, we used StarBeast 2 (Ogilvie et al. 2017) which

242 compared to BEAST better accounts for species trees vs. gene trees and for intraspecific vs.

243 interspecific events. For the StarBeast analyses we used the traditionally recognized taxa as

244 terminal units in an analytical population size integration model, a Beast named extended

245 substitution model, a birth death model, and either a strict molecular clock or a uncorrelated

246 relaxed molecular clock; four independent runs of 50 millions and sampling each 50000

247 generations were performed and the data were analyzed as previously commented for Beast

248 analysis. Finally, the best approach of molecular clock evolution was obtained trough marginal

249 likelihood comparisons following a Nested Sampling approach (Maturana et al. 2018).

250 To calibrate the dating analyses in Starbeast we used five different calibration

251 approaches of the molecular clock in order to assess the timing of the Herichthys phylogeny

252 with respect to the main biogeographic hypothesis, i.e. PdM vicariance vs. an earlier

253 colonization prior to formation of PdM. The calibrations are based on fossil and Middle

254 America relevant geological constrains and also use a secondary calibration from one multilocus

255 study that used all available Neotropical cichlid fossils for calibrations (Musilová et al., 2015),

256 but most of which are too distant phylogenetically to be applied to our single locus mtDNA

257 phylogeny directly. The same fossils have also been used for calibration in Tagliacollo et al.

258 (2017), who however additionally used the highly questionable constrain of a minimum age of

259 cichlids set at $95 \mathrm{Ma}$. This additional constrain explains the much older reconstructed dates

260 compared to Musilová et al. (2015). Since the dates are much older due to this additional

261 constrain than Musilová et al. (2015) there is no need to include Tagliacollo et al. (2017) among

262 our time constraints in testing the much younger PdM. No other fossils and Middle America

263 relevant geological constraints have so far been put forward in publications.

264 Analysis I follows Říčan et al. (2013) and includes one fossil plus two geological

265 calibrations. Calibration nodes: (1) The minimum age of the closest known fossil, Plesioheros

266 chauliodus (at 39.9-48.6 Ma; mean 44.25 Ma with SD = 2.7; Matschiner (2019), in their latest

267 review published after our analyses, gives 40-45 Ma as the most probable age of the fossil bed),

268 node all heroine cichlids except Hypselecara plus Hoplarchus; (2) The split between Cuba and

269 Hispaniola (at 20-25 Ma; mean 22.5 Ma with SD = 1.5), node between Cuban (Nandopsis

270 tetracanthus) and Hispaniolan (Nandopsis haitiensis) species; and (3) The separation of the

271 Orinoco and Magdalena drainage basins by the final rise of the Cordillera Oriental (10.1-11.8 
272 Ma; mean $10.95 \mathrm{Ma}$ with SD = 0.6), node between Caquetaia sp. cf. kraussii and Caquetaia 273 spectabile.

$274 \quad$ Analysis II uses the same two geological calibrations as above but excludes the direct

275 fossil calibration by Plesioheros chauliodus owing to its old age and possible influence on the

276 only single mtDNA marker used in the present study (vs. four mtDNA and three nDNA markers

277 in Říčan et al., 2013).

278 Analysis III on the other hand only uses the fossil Plesioheros chauliodus calibration as

279 above to compare its results with just the two geological calibrations.

280

Analysis IV is based on Musilová et al. (2015) who used a wider sampling of fossils for

281 calibrations. We employ here a secondary calibration based on their study, the split of the genus

282 Caquetaia, with a mean of $23 \mathrm{Ma}, \mathrm{SD}=2$.

283 As described in the introduction the calibration points in analyses I-IV cover the younger 284 range of dated phylogenies that are in conflict with the PdM calibration (i.e. Concheiro Pérez et 285 al. 2007; Ŕíčan et al. 2013; Musilová et al. 2015). We have thus omitted analyses that would be 286 calibrated from studies that suggest even older dates for cichlid phylogenies (e.g. Matschiner et 287 al. 2017; Tagliacollo et al. 2017; López-Fernández et al. 2013) because these are obviously even 288 more in conflict with the PdM calibration.

289 Finally, Analysis V employs only the geological PdM calibration and is used to compare 290 the PdM calibration with the other analyses.

291 Species delimitation analyses

292 For species delimitation analyses we have used cytb data since it is the only available

293 dataset with sufficient resolution and with sufficient specimen and locality sampling to be useful

294 for molecular-based species delimitation analyses. We have employed three different

295 delimitation approaches, the General Mixed-Yule Coalescent (GMYC) and the Poisson tree

296 processes (bPTP) that were designed for delimiting species based primarily on single molecular 297 markers, and the coalescent approach implemented in Starbeast. The GMYC model (Pons et al. 298 2006; Fujisawa and Barraclough 2013) is frequently used in empirical studies (Fontaneto et al. 299 2008; Monaghan et al. 2009; Carstens and Dewey 2010; Vuataz et al. 2011; Powell 2012) and 300 the newer bPTP model (Zhang et al. 2013) has been shown to even outperform the GYMC 301 method where distances between species are small. Both methods outperform OTU-picking 302 methods (relying on simple sequence similarity thresholds) and are more robust to cases where 
303 the barcoding gap is absent (Zhang et al. 2013). The bPTP was run on the RaxML tree and the 304 GMYC analysis was run on the ultrametric tree obtained from BEAST using a single threshold.

305 Both analyses were run at the freely available interface (http://species.h-its.org/) and the GMYC 306 analysis also in the splits library in R (Ezard et al. 2009). Unlike the two previous methods

307 Starbeast analysis requires that the haplotypes are assigned to a priori species. We have used the 308 traditionally recognized species (sensu Pérez-Miranda et al. 2018) for this analysis since they

309 are not conflicted by the trees generated by RaxML and Beast (which all gave similar

310 topologies). We have run all three delimitation analyses with the inclusion of only one, the most

311 closely related, outgroup (the genus Vieja).

312 Biogeographical reconstructions

313 We use two different hierarchical sets of biogeographical reconstructions using three

314 different molecular data sets in this study. The first biogeographic analysis reconstructs the

315 biogeographic history within the genus Herichthys and the ancestral area within the genus based

316 on the mtDNA cytb dataset. As terminal biogeographic units for the analysis we have used

317 Herichthys endemism areas (HEAs).

318 The second set of biogeographic analyses reconstructs the biogeographic history of

319 Herichthys within Middle America. For the second biogeographic analysis of Herichthys within

320 Middle America we have used two phylogenies, the multilocus yet mtDNA-dominated dated

321 phylogeny of Říčan et al. (2013) and the nDNA ddRAD phylogeny of Říčan et al. (2016). The

322 ddRAD phylogeny from Říčan et al. (2016; supplementary material 5 in Říčan et al., 2016) is

323 very robust with all basal nodes connecting the major lineages (subtribes) having a posterior

324 probability of 1 and hence with a much better node support than the multilocus mtDNA-

325 dominated phylogenies of Říčan et al. (2013) and Tagliacollo et al. (2017). Additionally, there

326 are many significant mito-nuclear conflicts between the mtDNA-dominated phylogenies (Říčan

327 et al., 2013; Tagliacollo et al., 2017) and the nDNA (ddRAD and exon-based) phylogenies of

328 Říčan et al. (2016) and Ilves et al. (2018) the influence of which on the biogeographical

329 reconstruction we explore in the two phylogenies. The phylogenies of Říčan et al. (2013) and

330 Ríčan et al. (2016) additionally have by far the best taxonomic sampling (both include all but one

331 genus of Middle American and Caribbean cichlids and their most closely related outgroups) and

332 are thus the best suited phylogenies for detailed biogeographical reconstructions. The ddRAD

333 phylogeny of Říčan et al. (2016) additionally has better support values than the exon-based 
334 phylogeny of Ilves et al. (2018) that lacks support at several of these nodes and which

335 additionally does not include several important lineages.

336 For the biogeographical reconstructions within Middle America using the two

337 phylogenies of Říčan et al. $(2013,2016)$ we have used cichlid endemic areas (CEAs; sensu Říčan

338 et al. 2016) as terminal units, since these are the most fine-scaled units that can be used for the

339 analyses (Říčan et al., 2016) and as such provide the most detailed resolution for regional

340 biogeography reconstructions (much more detailed than e.g. the ichthyological provinces used in

341 Říčan et al. 2013). The dating of the reconstructed biogeographical events is provided by the

342 phylogeny of Říčan et al. (2013).

343 Reconstruction of ancestral areas for all nodes in the phylogenetic trees in each analysis (both

344 within Herichthys as well as within all of Middle America) was carried out using the event-based

345 Bayesian statistical dispersal-vicariance analysis (S-DIVA; implemented in RASP 2.0; Yu et al.

346 2010). Distributions of all terminals at the level of the used geographical units were input into S-

347 DIVA. The analyses were carried out using a number of different 'maxareas' options in S-DIVA

348 up to the maximum number of areas in the analysis. If results are the same for all 'maxareas'

349 analyses, then just this one result is reported. If results differ between the 'maxareas' analyses, a

350 summary of all analyses is supplied at the relevant node.

351 An important point to consider in biogeographical reconstructions is extinctions. In our study

352 of a very dispersal-limited animal group and in the absence of a fossil record, we reconstructed

353 extinctions in the following manner by taking advantage of the rarely available but in our

354 phylogenies (Říčan et al., 2013, 2016; present study) specifically targeted complete species

355 sampling and the use of very fine-scaled biogeographical units (HEAs and CEAs; see above). If

356 in our biogeographical reconstructions at a given node, two or more directly neighboring areas

357 meet, then at this node, there is no need to postulate any extinction and a vicariant event is most

358 likely. In other situations, one or more extinctions (depending on the geographical configuration

359 of the biogeographic units) in the intervening area(s) are postulated.

360 Our biogeographic analyses are accompanied by DEM simulations of sea-level-caused

361 changes in palaeogeography of northern Middle America based on the sea-level curves of Haq et

$362 a l$. (1987) and we compare these simulations with paleogeographic maps of past configurations

363 of northern Middle America (https://deeptimemaps.com/). For the DEM analysis, a clip for the 
364 study area was extracted from a 30-arc seconds raster from the US Geological Survey

365 (https://geo.nyu.edu) using the raster library 2.6.7 (Hijmans and van Etten 2014) in R version

366 5.1. Afterwards, the raster was imported to ArcMap 10 (ESRI, 2011) and the pixels were

367 classified in three categories, $<60 \mathrm{~m}$ a.s.1. to approximate high sea levels reached during

368 Miocene and Pliocene, up to $1000 \mathrm{~m}$ a.s.l. that is the altitudinal limit that cichlids usually reach

369 and above $1000 \mathrm{~m}$ a.s.1. where we have few rare collections at $1300 \mathrm{~m}$ a.s.1. (Fig. 1).

\section{Results}

371 Phylogeny of Herichthys based on cytb

372 The 164 Herichthys cytb sequences correspond to 142 haplotypes demonstrating strong

373 population structuring without widespread haplotypes. The phylogenetic relationships of the cyt $b$

374 dataset with the herein extended sampling (Figs. 2-3; Figs. S1-S2) confirmed the results of Ríčan

375 et al. (2016) and Pérez-Miranda et al. (2018), but also revealed several new points. The two main

376 clades within Herichthys are recovered with high robustness as are the relationships between the

377 species with all supraspecific nodes except one strongly supported (Fig. 2; Figs. S1-S2). New

378 results include 1) the non-monophyly of the species $H$. tamasopoensis which was monophyletic

379 in Říčan et al. (2016) and Pérez-Miranda et al. (2018) and 2) the phylogenetic position of $H$.

380 molango, which has previously not included, and is here found nested within $H$. pantostictus. All

381 species sensu Pérez-Miranda et al. (2018) except H. tamasopoensis are thus strongly supported

382 by the phylogeny and support values. The species rejected in Pérez-Miranda et al. (2018) are

383 thus also rejected here with the addition of $H$. molango.

384 Species delimitation analyses within Herichthys

$385 \quad$ Our phylogenetic results strongly support all the species recognized in the review of

386 Pérez-Miranda et al. (2018) except H. tamasopoensis. Delimitation of the species based solely on

387 the here used mtDNA cyt data is however weaker (Fig. 2). The GMYC and Starbeast

388 delimitation analyses provided more comparable results but failed to separate $H$. bartoni from $H$.

389 labridens, H. steindachneri from H. pame, and logically H. tamasopoensis from H. carpintis

390 (since the former is nested as non-monophyletic within the latter). The GMYC analysis

391 additionally failed to delimit H. tepehua from the previous two species. The remaining species

392 were delimited correctly by both analyses. The bPTP analysis provided somewhat different

393 delimitation since on one hand it only delimited $H$. minckleyi and $H$. cyanoguattus within the $H$.

394 cyanoguttatus group but on the other hand delimited all species in the H. labridens group except 
395

396

397

398

399

400

401

402

403

404

405

406

407

408

409

410

411

412

413

414

415

416

417

418

419

420

421

422

423

424

425

426

H. labridens from $H$. bartoni and additionally delimited two divergent haplotypes of $H$. steindachneri as distinct species-level groups (Fig. 2).

Phylogeography and timeframe of speciation events in Herichthys

The biogeographical analysis within the genus Herichthys (Fig. 2) reconstructed a wide ancestral area that includes the whole present distribution of the genus. Given the wide reconstructed ancestral node, the majority of Herichthys diversification is based on our biogeographic analysis a series of vicariant events (Fig. 4). The separation into the two main clades was nearly completely vicariant (with overlap only in area b, the Pánuco basin; Fig. 2), with the H. labridens group after being limited to highlands of the Pánuco basin and $H$. cyanoguttatus mostly to the lowlands of the rest of the area. The basal node in Herichthys is dated between 8.9 to $14.4 \mathrm{Ma}$ (Fig. 3)

The H. labridens group biogeography is nearly completely vicariant (with sympatry of two species pairs, however, and a later dispersal within $H$. pantostictus). The supraspecific allopatric nodes in the H. labridens group are dated between $4.1-6.2$ to $5.7-8.9 \mathrm{Ma}$ in analyses I to IV (Fig. 2). The sympatric supraspecific nodes are dated between $0.3-0.5$ in the younger pair and $0.8-1.2 \mathrm{Ma}$ in the older pair (Fig. 3).

The $H$. cyanoguttatus group biogeography is completely vicariant with the first two species to diverge being the northernmost (H. minckleyi) and southernmost (H. deppii), followed later by more tightly spaced vicariant events in the central area, that again included a northern (H. cyanoguttatus) and southern species (H. tepehua) diverging from the centrally distributed species (H. carpintis, which in our analyses contains the parapatric H. tamasopoensis). The allopatric supraspecific nodes in the $H$. cyanoguttatus group are dated between (except the $H$. carpintis/H. tamasopoensis node) $1.6-2.4$ to $4.4-7.0 \mathrm{Ma}$ (Fig. 3) The speciation events in both species groups thus fall into the same time window. Our biogeographic reconstructions suggesting vicariance as the predominant speciation mode for the allopatric species and the reconstructed dates (analyses I-IV) for these events in the lowland species correspond with high sea-levels that existed during the Miocene/Pliocene boundary (Fig. 3)

\section{Dating of Herichthys at PdM}

Our dating analyses of the Herichthys cytb phylogeography (Fig. 3) reject the postulated PdM vicariance and favor older dispersal prior to the formation of the PdM using either a strict or a relaxed molecular clock, due that similar results were obtained with both approaches, we only present the divergence dates of the strict molecular clock which obtained a higher 
427 likelihood value in the five calibrations (Table S2). All analyses that exclude the PdM

428 calibration (analyses I-IV) reconstruct the age of Herichthys diversification to be between two 429 and three times older than the PdM calibration in Starbeast analyses (10.0 to $17.1 \mathrm{Ma}$ ) (Fig. 3)

430 vs. 5 to $7.5 \mathrm{Ma}$ of PdM. The PdM calibration analysis (calibrated with 7.5 Ma; Fig. 3) also

431 reconstructs a very young overall cichlid diversification time frame.

432 Biogeography of cichlids at PdM

433 The reconstructed dates of divergence of Herichthys from its sister groups 10.0 to 17.1

434 Ma correspond to high sea-levels during the early and middle Miocene (Fig. 3). Further

435 correspondence with global sea-levels is seen in the reconstructed date of the basal node of

436 Herichthys, which falls into the time period when the sea levels experienced a significant drop

437 from more than $100 \mathrm{~m}$ above present sea levels to close to present-day sea levels during the late

438 Miocene (Haq et al. 1987; Fig. 3, Fig. S3). The wide reconstructed ancestral area within the

439 genus also corresponds with the sea-level changes since prior to the late Miocene sea level drop 440 a continuous ancestral area of the genus would not have been possible (Figs. 1 and 3).

441 The Miocene/Pliocene divergences between the lowland species of Herichthys, likely

442 caused by the high sea-levels (Fig. 3), are based on our biogeographical reconstructions and 443 datings of the whole Middle American cichlids accompanied by contemporaneous extinctions 444 among the closely related allopatric lowland genera Vieja and Maskaheros (Fig. 4 and Fig. S3).

445 The early to middle Miocene reconstructed date of divergence of Herichthys from its 446 sister groups (10.0 -17.1 Ma in the Starbeast analyses I-IV, Fig. 3), corresponding and thus 447 likely also caused by the high sea-levels (Fig. 3), is also accompanied by reconstructed 448 extinctions (Fig. 4; Fig. S3), in this case in the whole intervening area between the Herichthys 449 ancestral area (Fig. 2) and the ancestral area of the whole herichthyine clade (Fig. 4; Fig. S3). 450 All the reconstructed extinction events are localized into the lowland area between the two 451 reconstructed ancestral areas strengthening the cause by the high sea-levels. Since the 452 reconstructed extinctions exhibit very robust correspondence with increased sea levels, and 453 since our dating analyses are in conflict with the PdM as a vicariant event, the isolation of the 454 Herichthys ancestor was thus more likely achieved by high sea levels than by vicariance caused 455 by the formation of the PdM. The differentiation of Herichthys from the remainder of its clade 456 was thus not a vicariant event, but a dispersal event followed by isolation caused by local 457 extinctions. 
458 Discussion

459 Species diversity and Biogeography of the genus Herichthys

460 Species diversity in Herichthys is complex (reviewed by Pérez-Miranda et al. 2018) and

461 the expanded sampling in the present study strongly supports ten species. The herein employed

462 species delimitation methods did not provide converging or inspiring results. The results of all

463 three analyses (GMYC, bPTP and Starbeast) all suggest a more conservative classification

464 delimiting in agreement only eight species. The recently diverged sympatric sister-species that

465 are highly divergent morphologically (Pérez-Miranda et al. 2018) have not been recovered by the

466 delimitation methods, even though they form in all here employed phylogenetic analyses

467 reciprocally monophyletic and strongly supported species.

468 Two recently described species (H. pratinus and H. molango) and one traditionally

469 recognized species (H. tamasopoensis) are not supported by any of the phylogenetic analyses nor

470 delimitation analyses of the cytb dataset (Fig. 2) because they are not monophyletic and their

471 non-monophyly within two other species (H. pantostictus and H. carpintis; Figs. S1-S2).

472 The interesting (or problematic) result of the cytb species delimitation analyses are the

473 deep clades within $H$. steindachneri as the species is a relatively recently diverged sympatric

474 sister species of $H$. pame, and it was hypothesized from the larger distribution and

475 ecomorphology of $H$. pame that this species is closer to the ancestor of the species pair (Artigas

476 Azas 2008; Pérez-Miranda et al. 2018)

477 The limited resolution of the molecular species delimitation analyses coupled with only

478 modest morphological differentiation, especially within the two species groups well

479 demonstrates the difficulty of species classification in the genus. The employed single locus

480 species delimitation, such as GMYC and bPTP, are fast protocols that allow identifying putative

481 species; however, they have several limitations (Amado et al. 2011; Colatreli et al. 2012; Farias

482 and Hrbek 2008; Willis 2017; Carvalho et al. 2018; Machado et al. 2018). Further studies

483 including independent genomic data with a robust locality sampling are thus necessary to

484 provide hypotheses of species boundaries (Zhang et al. 2011). On the other hand, Starbeast is a

485 method designed to estimate both gene tree and species tree under a coalescent theory from a

486 large number of markers that avoid the caveats of concatenation of markers (Ogilvie et al.

487 2017). However, it requires the definition of "a priori" taxon labels that could be useful to

488 synonymize species but not to postulate putative cryptic species. 

area significantly prior to the suggested vicariance by PdM 5 to $7.5 \mathrm{Ma}$ (Hulsey et al. 2004;

491 Hulsey et al. 2010). The colonization of the present area occupied by Herichthys occurred based 492 on our analyses prior to $10.0-17.1 \mathrm{Ma}$ (based on Starbeast analyses I-IV), i.e. the dated split 493 between Herichthys and its sister-groups. The proposed divergence of this genus (and many 494 other groups where this calibration has been used; see Introduction and below) at the PdM as a 495 vicariance event is thus not compatible with other dating constraints as demonstrated in the 496 present study, the PdM calibration being a clear outlier among the dating constraints.

The use of the PdM calibration in order to test events across the PdM is additionally 498 clearly a product of circular reasoning (Kodandaramaiah 2011; Ho et al. 2016). Such a situation 499 has to be avoided, either by excluding the vicariant event in question from the calibration or by 500 using it together with other calibrations (Kodandaramaiah 2011; Reznick et al. 2017) as has been 501 done in this study. Previous studies that utilized this circular reasoning in dating of divergences 502 include the cichlids and Herichthys in particular (Hulsey et al. 2004; Hulsey et al. 2010), and 503 also non-cichlid genera such as Astyanax, Pseudoxiphophorus, and Xiphophorus (Ornelas et al. 504 2008; Agorreta et al. 2013; Culumber et al. 2016). Palacios et al. (2016) found an estimated age 505 of 5.28 Ma for the subgenus Mollienesia, using a universal mitochondrial mutation rate that 506 coincided with the formation of PdM, but with the use of a secondary calibration point of Ho et 507 al. (2016) that is based on a wide fossil record (Betancur-R et al. 2013), the time estimates were 508 reduced drastically to $1.28 \mathrm{Ma}$ and therefore postdating the vicariant hypothesis for the species 509 north and south of PdM.

510 The reconstructed biogeography of the separation of Herichthys from its closest relatives 511 provides an even stronger case (as opposed to just dating) for colonization prior to PdM instead 512 of vicariance at PdM. Reconstruction of ancestral areas in both the nuclear ddRAD topology 513 (Fig. 4) as well as mtDNA-dominated topology (Fig. S3) identifies the same set of extinctions in 514 the intervening area between Herichthys and its closest relatives. The dating of the reconstructed 515 extinctions (Fig. S3) clearly demonstrate that isolation of Herichthys from its closest relatives is 516 older than the formation of the PdM (10 -14 Ma vs. 7.5 to $5 \mathrm{Ma}$ in the original dating of Ř́čan et 517 al., 2013; see Fig. S3; 10 - 17. 1 Ma in analyses in this study; Fig. 3). These reconstructed 518 extinctions additionally exhibit a very strong correspondence with increased sea levels that 519 existed during the period of the divergence in early and middle Miocene (24-12 Ma; Figs. 1, 3; 
520 Fig. S3). The isolation of Herichthys from its closest relatives was thus not a vicariant event at

521 the PdM but a dispersal event followed by isolation through extinctions probably caused by high 522 sea levels.

523 Implications for the Biogeography of Middle America and the Caribbean

524 The geological literature offers several dating constraints for colonization and

525 diversification of cichlids in Middle America and the Caribbean. Except for one, the PdM, none

526 were so far used in any publications focusing on cichlid colonization and diversification in

527 Middle America and it is thus timely to introduce them here and compare them with the results

528 of this study and published dated phylogenies of the Middle American cichlids and cichlids in

529 general. The geological constraints for cichlid evolution in Middle America and the Caribbean

530 are of great importance to the debate regarding cichlid dating, in general, as Middle America and

531 the Caribbean is the only area of cichlid distribution where the group occurs on present or former

532 relatively small islands within former island chains (Říčan et al. 2013), while most other cichlids

533 are continental (even Madagascar is much larger than any of the islands in past and present

534 configurations of Middle America and the Caribbean). Only a handful of cichlid species among

535 the thousands of species is known from marine or brackish conditions (Kullander 1983; Murray

536 2001; Říčan et al. 2016) and the degree of capability of marine crossings remains debated, but an

537 island chain setting clearly does provide better constraints on cichlid biogeography than do

538 continental settings.

539 The oldest geological evidence for continuity in Caribbean land environments is from 37

$540 \mathrm{Ma}$ (Iturralde-Vinent and MacPhee 1999; Iturralde-Vinent 2004a,b; MacPhee and Iturralde-

541 Vinent 2005). This means that older terrestrial (freshwater) habitats that would have remained

542 subaerial are not known at the moment. Therefore, all postulated colonizations of the Greater

543 Antilles older than this date (e.g., Tagliacollo et al. 2017 at 45-50 Ma for cichlids and 56 Ma for

544 poeciliids; López-Fernández et al. 2013 at 55 Ma for cichlids; and, marginally, Matschiner et al.

5452017 between 44 and $31 \mathrm{Ma}$ ) do not explain where and how these fishes have survived in the

546 Antilles. During these old times, there was virtually no land in the Antilles - they were almost

547 completely under the sea. Similarly, before ca $35 \mathrm{Ma}$ (all through the Cretaceous from 75-70

$548 \mathrm{Ma}$ ), most of the Maya block was also under sea (Iturralde-Vinent 2004 a,b). Continuous land,

549 however, existed in the area of the present diversity center of cichlids (Říčan et al. 2016) in the

550 south of the Maya block. Colonization dates older than 37 Ma would thus first need to reach 
551 Middle America (the Maya and Chortis blocks) and only later from there colonize the Greater

552 Antilles. The Chortis block continued its movement toward the east and south from west of

553 present-day SE Mexico and in the Lower Oligocene, $35 \mathrm{Ma}$, united with the Maya block along

554 the presently still active sutures, defining the present territory of Guatemala. Before this date, the

555 Chortis and Maya blocks were not in contact and, additionally, large portions of both were

556 covered by shallow seas (from Iturralde-Vinent $2006 \mathrm{a}, \mathrm{b}$ ).

557 The Chortis block underwent massive volcanic activity that created the middle Miocene

558 ignimbrite province (the High Volcanic Plateaus, HVP) between 20-14 Ma (Rogers et al., 2002,

559 2007; Jordan et al. 2006; Molina Garza et al. 2012). This volcanic activity was directly linked

560 with the docking of Lower Central America (LCA) in the form of the Miocene Volcanic Arc

561 (MVA) at $22 \mathrm{Ma}$ and its subduction under the Chortis block (Coates and Obando 1996; Coates

562 1997; Coates et al. 2004; Kirby and MacFadden 2005; Kirby et al. 2008). At the same time also

563 began the formation of the San Juan basin between the southern terminus of the Chortis block

564 and LCA. Interestingly, cichlid fishes, based on biogeographic analyses (Fig. 4 and Fig. S3),

565 underwent significant extinctions in all areas of the HVP and most neighboring northern areas on

566 the Chortis block and, importantly, virtually nowhere else in Central America. These extinctions

567 are independently dated between 24-13 Ma (following the dating analysis by Říčan et al. 2013;

568 Fig. S3). The extinctions happened not only in highland areas of the HVP, but also in the low-

569 lying areas of the Chortis block that lie outside major concentrations of the ash falls. The datings

570 of the extinctions (24-13 Ma) in the highlands coincides with the HVP (20-14 Ma), while

571 extinctions in the lowlands coincide as well with HVP as well as with high sea levels during the

572 Late Oligocene to Middle Miocene (23-14 Ma). The coincidence is striking and we are not aware

573 of any other events that would explain these extinctions that produced the depauperate cichlid

574 faunas of northern Nuclear Central America (Honduras, El Salvador, northern Nicaragua) and

575 the concentration of all lineages in the San Juan basin, the youngest area of Nuclear Central

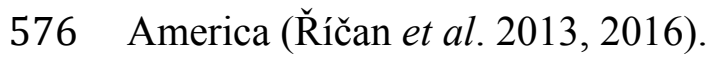

577 The emergence of LCA in the form of the MVA (22 Ma) posits the oldest possible date

578 for colonization of LCA and of the San Juan basin because before that, these areas were

579 submerged below the sea. The cichlid colonizations of LCA, as independently dated by Říčan et

580 al. (2013; Fig. S3), started at the latest by $18 \mathrm{Ma}$, and all lineages were established in LCA at the

581 latest by $9 \mathrm{Ma}$. 
The novel dating constraints for cichlid diversification in Middle America can thus be

583 summarized as follows: (1) Maximum and minimum age for colonization of Middle America

584 through the Greater Antilles 37-33 Ma. The dating by Říčan et al. (2013) is thus 6 Ma below the

585 maximum age (Fig. S3); (2) Maximum age for colonization of LCA is $22 \mathrm{Ma}$. The dating by

586 Ŕíčan et al. (2013) is thus 4 Ma below the maximum age; (3) Age of HVP 20-14 Ma and dated

587 cichlid extinctions in HVP 24-13 Ma. The dating by Říčan et al. (2013) is thus for this node at its

588 maximum age; (4) The extinctions of cichlids in low-lying areas were likely influenced by the

589 high sea levels of the Late Oligocene to Middle Miocene (23-14 Ma) and have a terminal age of

590 12.5 Ma on the Chortis block and 10.5 on the Maya block. The dating by Ríčan et al. (2013) is

591 thus only 1.5-3.5 Ma younger than maximum age; (5) The extinctions of cichlids in low-lying

592 areas of the Maya block likely caused by the high sea levels during the early Pliocene (5.5-4.5

593 Ma) are in Říčan et al. (2013; Fig. S3) dated exactly within this timeframe and thus the cichlid

594 dating at these nodes cannot be any older or younger.

595 The aforementioned geological constraints on dating of cichlid phylogenies in Middle

596 America postulate that cichlid evolution in the area cannot be significantly older (and definitely

597 not younger) than proposed in the dated framework of Ríčan et al. (2013) and that the five

598 constraints are coherent among each other. All of these five novel geological constraints, as well

599 as the constraints used in the present study, in Říčan et al. (2013), in Musilová et al. (2015), in

600 Tagliacollo et al. (2017), or in Matschiner et al. (2017) are on the other hand in conflict with the

$601 \mathrm{PdM}$ constraint, since all give much older divergences at the PdM than are compatible with

602 vicariance caused by the PdM. The PdM calibration on the other hand results in one of the

603 youngest dates for cichlid evolution (this study; Hulsey et al. 2004, 2010), based on this study

604 even marginally younger (at the comparable node of Hypselecara divergence from its sister-

605 group) than in Friedman et al. (2013), so far the youngest and clearly outlying study of cichlid

606 divergence dates (Matschiner 2019). In summary, the five novel constraints examined here in the

607 discussion of Middle American palaeogeography as bounds for colonization and diversification

608 of cichlids in Middle America and the Greater Antilles suggest that the cichlid diversification in

609 Middle America can be, at the most, $6 \mathrm{Ma}, 4 \mathrm{Ma}$, and 1.5-3.5 Ma older (in the respective

610 succession of nodes from oldest to youngest) than the dating frame reconstructed by Říčan et al.

611 (2013), while the two youngest constrained nodes are at their maximum age. This demonstrates

612 that any cichlid datings significantly older (e.g. López-Fernández et al. 2013 and all other studies 
613 that used Gondwana vicariance as the sole calibration constraint; as well as Tagliacollo et al.

614 2017; and marginally Matschiner et al. 2017) or younger (Hulsey et al. 2004; Hulsey et al. 2010;

615 Friedman et al. 2013) than the bounds presented here have to be taken as highly questionable

616 from the point of view of Middle American paleogeography and cichlid biogeography unless we

617 allow the option that cichlid biogeography is completely independent from ecological and

618 geological constraints.

619

Conclusions

620

The results of this study suggest that in opposition to the majority of previously published

621 literature regarding freshwater fish divergence across the Punta del Morro (PdM) the PdM has in

622 the here studied genus Herichthys not acted as a vicariant event (at 7.5 to $5 \mathrm{Ma}$ ), but instead the

623 ancestor of Herichthys colonized its ancestral distribution area to the north of it through a

624 dispersal event prior to 10 to $17 \mathrm{Ma}$ and that the separation of Herichthys from its closest clades

625 was due to extinctions in the intervening area caused by high sea levels during the early to

626 middle Miocene, not the result of the uplift of Punta del Morro between 5 to $7.5 \mathrm{Ma}$. The old

627 divergence of Herichthys is also supported by additional novel constraints from Middle

628 American geology and palaeogeography introduced in this study that suggest that compared to

629 the dated framework of cichlid evolution in Middle America of Ríčan et al. (2013) the actual

630 evolution of the group in Middle America can be, at the most 1.5 to $6 \mathrm{Ma}$ older and definitely not

631 younger. This demonstrates that any published cichlid datings significantly older or younger than

632 the bounds presented here have to be taken as highly questionable from the point of view of

633 Middle American paleogeography and cichlid biogeography unless we allow the option that

634 cichlid biogeography is completely independent from ecological and geological constraints.

\section{Supplementary material}

636 Supplemental Table S1. List of the material analyzed in this study.

637 Supplemental Table S2. List of the material analyzed in this study.

638 Supplemental Figure S1. Neighbour joining topology of the cytb Herichthys haplotype dataset.

639 Supplemental Figure S2. RAXML topology of the cytb Herichthys haplotype dataset. 
640 Supplemental Figure S3. BEAST dated phylogeny of the multilocus nDNA-mtDNA dataset of

641 the Middle American and related Cichlidae showing molecular clock date estimates and

642 biogeographical reconstructions used for discussion of novel constraints on Middle American

643 cichlid diversification.

\section{Additional Information and Declarations}

645 Competing Interests

646 The authors declare that they have no competing interests.

647 Author Contributions

648

649

Fabian Pérez-Miranda performed the experiments, analyzed the data, prepared figures and/or

650

651

652

653

654

655

656

657

658

659

660

661

662

663

664

665 tables, authored or reviewed drafts of the paper, approved the final draft.

Omar Mejía conceived and designed the experiments, analyzed the data, contributed reagents and materials, authored or reviewed drafts of the paper, approved the final draft.

Benjamín López performed the experiments, prepared figures and/or tables, authored or reviewed drafts of the paper, approved the final draft.

Oldřich Říčan conceived and designed the experiments, analyzed the data, prepared figures and/or tables, authored or reviewed drafts of the paper, approved the final draft.

\section{Data Availability}

The new sequences generated in this study are available at GenBank under the accession numbers MK481080-MK481126.

\section{Funding}

666 This work was partially funded by SIP projects number 20180849 and 20190100.

\section{Acknowledgments}

668 We thanks to Juan Carlos Fontanelli from Balneario cascadas de Tamasopo and the staff of

669 Rancho el Jobo for the facilities provided for specimen collection. We also thanks to the

670 associate editor Thomas Hrbek and two anonymous reviewers for their helpful comments to

671 improve the manuscript. 


\section{References}

673 Agorreta A, Domínguez-Domínguez O, Reina RG, Miranda R, Bermingham, E, Doadrio, I

674 (2013). Phylogenetic relationships and biogeography of Pseudoxiphophorus (Teleostei:

675 Poeciliidae) based on mitochondrial and nuclear genes. Mol Phylo Evol 66: 80-90.

676 https://doi.org/10.1016\%2Fj.ympev.2012.09.010

677

678

679

Aljanabi SM, Martinez, I (1997). Universal and rapid salt-extraction of high quality genomic

680

681

682

683

684

685

686

687

688

689

690

691

692

693

694

695

696

697

698

699

700

701

702

703

704

705

706

707

708

709

710

711

712

713

714 DNA for PCR-based techniques. Nucleic Acids Res 25: 4692-4693.

https://doi.org/10.1093\%2Fnar\%2F25.22.4692

Amado MV, Farias IP, \& Hrbek T (2011). A molecular perspective on systematics, taxonomy and classification Amazonian discus fishes of the genus Symphysodon. Int J Evol Biol: 2011. https://doi.org/10.4061\%2F2011\%2F360654

Artigas-Azas JM. 2008. "Herichthys sp. "white labridens”". Cichlid News Magazine 17: 23-28.

Barluenga M, Stölting KN, Salzburger W, Muschick M, Meyer A (2006). Sympatric speciation in Nicaraguan crater lake cichlid fish. Nature 439: 719-723.

https://doi.org/10.1038\%2Fnature04325

Bermingham E, Martin AP (1998). Comparative mtDNA phylogeography of neotropical freshwater fishes: testing shared history to infer the evolutionary landscape of lower Central America. Mol Ecol 7: 499-517. https://doi.org/10.1046\%2Fj.1365-294x.1998.00358.x

Betancur-R R, Broughton RE, Wiley EO, Carpenter K, López JA, Li C, Holcroft NI, Arcila D, Sanciangco M, Cureton JC, Zhang F, Buser T, Campbell MA, Ballesteros JA, Roa-Varon A, Willis S, Borden WC, Rowley T, Reneau PC, Hough DJ, Lu G, Grande T,Arratia G, Ortí G. . (2013). The tree of life and a new classification of bony fishes. PLoS Curr: 5.

https://doi.org/10.1371/currents.tol.53ba26640df0ccaee75bb165c8c26288

Burress ED, Alda F, Duarte A, Loureiro M, Armbruster JW, Chakrabarty P (2018).

Phylogenomics of pike cichlids (Cichlidae: Crenicichla): the rapid ecological speciation of an incipient species flock. J Evol Biol 31: 14-30. https://doi.org/10.1111\%2Fjeb.13196

Carstens BC, Dewey TA (2010) Species delimitation using a combined coalescent and information-theoretic approach: an example from North American Myotis bats. Syst Biol 59:

715 400-414. https://doi.org/10.1093\%2Fsysbio\%2Fsyq024 
716

717

718

719

720

721

722

723

724

725

726

727

728

729

730

731

732

733

734

735

736

737

738

739

740

741

742

743

744

745

746

747

748

749

750

751

752

753

754

755

756

757

758

759

760

761
Carvalho APC, Collins RA, Martínez JG, Farias IP, Hrbek T (2018). From shallow to deep divergences: mixed messages from Amazon Basin cichlids. Hydrobiologia 832:317-329. https://doi.org/10.1007\%2Fs10750-018-3790-x

Coates AG, Obando JA (1996) The geologic evolution of the Central America Isthmus. In: Jackson LBC, Budd AF, Coates AG (eds) Evolution and environment in tropical America. Chicago University Press, Chicago, pp. 21-56.

Coates AG, Collins LS, Aubry MP, Berggren WA. (2004) The geology of the Darien, Panama, and the late Miocene-Pliocene collision of the Panama arc with northwestern South America. Geol Soc Am Bull 116: 1327-1344. https://doi.org/10.1130\%2Fb25275.1

Coates AG (1997) The forging of Central America. In: Coates AG (ed) Central America: a natural and cultural history. Yale University Press, New Haven, pp. 1-37.

https://doi.org/10.2307\%2Fj.ctt1xp3sdf.6

Colatreli OP, Meliciano NV, Toffoli D, Farias IP, Hrbek T (2012). Deep phylogenetic divergence and lack of taxonomic concordance in species of Astronotus (Cichlidae). Int J Evol Biol: 2012. https://doi.org/10.1155\%2F2012\%2F915265

Concheiro-Pérez GAC, Říčan O, Ortí G, Bermingham E, Doadrio I, Zardoya R (2007).

Phylogeny and biogeography of 91 species of heroine cichlids (Teleostei: Cichlidae) based on sequences of the cytochrome b gene. Mol Phylo Evol 43: 91-110.

https://doi.org/10.1016\%2Fj.ympev.2006.08.012

Culumber ZW, Tobler M (2016). Ecological divergence and conservatism: spatiotemporal patterns of niche evolution in a genus of livebearing fishes (Poeciliidae: Xiphophorus). BMC Evol Biol 16: 44. https://doi.org/10.1186\%2Fs12862-016-0593-4

Elmer K, Lehtonen, T, Kautt AF, Harrod C, Meyer A. (2010a). Rapid sympatric ecological differentiation of crater lake cichlid fishes within historic times. BMC Biol. 8: 60. https://doi.org/10.1186\%2F1741-7007-8-60

Elmer K, Kusche H, Lehtonen T, Meyer A (2010b). Local variation and parallel evolution: morphological and genetic diversity across a species complex of neotropical crater lake cichlid fishes. Philos Trans Royal Soc B 365: 1763-1782. https://doi.org/10.1098\%2Frstb.2009.0271 
762 Elmer KR, Fan S, Kusche H, Spreitzer ML, Kautt AF, Franchini P, Meyer A. (2014). Parallel 763 evolution of Nicaraguan crater lake cichlid fishes via non-parallel routes. Nat Commun 5: 5168.

764 https://doi.org/10.1038\%2Fncomms6168

765

766

767

768

769

770

771

772

773

774

775

776

777

778

779

780

781

782

783

784

785

786

787

788

789

790

791

792

793

794

795

796

797

798

799

800

801

802

803

804

805

806

ESRI. (2011). ArcGIS Desktop: Release 10. Redlands, CA: Environmental Systems Research Institute.

Ezard T, Fujisawa T, Barraclough TG (2009). Splits: species' limits by threshold statistics. (R package).

Farias IP, Hrbek T (2008). Patterns of diversification in the discus fishes (Symphysodon spp. Cichlidae) of the Amazon basin. Mol Phylo Evol 49: 32-43.

https://doi.org/10.1016\%2Fj.ympev.2008.05.033

Fontaneto D, Boschetti C, Ricci C (2008). Cryptic diversification in ancient asexuals: evidence from the bdelloid rotifer Philodina flaviceps. J Evol Biol 21: 580-587.

https://doi.org/10.1111\%2Fj.1420-9101.2007.01472.x

Friedman M, Keck BP, Dornburg A, Eytan RI, Martin CH, Hulsey CD, Wainwright PC, Near TJ. (2013). Molecular and fossil evidence place the origin of cichlid fishes long after Gondwanan rifting. Proc R Soc Lond (Biol) 280: 20131733. https://doi.org/10.1098\%2Frspb.2013.1733

Fujisawa T, Barraclough TG (2013). Delimiting species using single-locus data and the Generalized Mixed Yule Coalescent approach: a revised method and evaluation on simulated data sets. Syst Biol 62: 707-724. https://doi.org/10.1093\%2Fsysbio\%2Fsyt033

Galtier N, Gouy M, Gautier C (1996). SEAVIEW and PHYLO_WIN: two graphic tools for sequence alignment and molecular phylogeny. Bioinformatics 12 : 543-548.

https://doi.org/10.1093\%2Fbioinformatics\%2F12.6.543

Haq BU, Hardenbol JAN, Vail PR. (1987). Chronology of fluctuating sea levels since the Triassic. Science 235: 1156-1167. https://doi.org/10.1126\%2Fscience.235.4793.1156

Hijmans RJ, Van Etten J (2014). Raster: Geographic data analysis and modelling (R package).

Ho AL, Pruett CL, Lin J (2016). Phylogeny and biogeography of Poecilia (Cyprinodontiformes: Poeciliinae) across Central and South America based on mitochondrial and nuclear DNA 807 markers. Mol Phylo Evol 101: 32-45. https://doi.org/10.1016\%2Fj.ympev.2016.04.032 
808

809

810

811

812

813

814

815

816

817

818

819

820

821

822

823

824

825

826

827

828

829

830

831

832

833

834

835

836

837

838

839

840

841

842

843

844

845

846

847

848

849

850

851

Hrbek T, Seekinger J, Meyer A. (2007) A phylogenetic and biogeographic perspective on the evolution of poeciliid fishes. Mol Phylo Evol 43: 986-998.

https://doi.org/10.1016\%2Fj.ympev.2006.06.009

Huidobro L, Morrone JJ, Villalobos JL, Álvarez F (2006). Distributional patterns of freshwater taxa (fishes, crustaceans and plants) from the Mexican Transition Zone. J Biogeo 33: 731-741. https://doi.org/10.1111\%2Fj.1365-2699.2005.01400.x Hulsey CD, de León FJG, Johnson YS, Hendrickson DA, Near TJ (2004). Temporal diversification of Mesoamerican cichlid fishes across a major biogeographic boundary. Mol Phylo Evol 31: 754-764. https://doi.org/10.1016\%2Fj.ympev.2003.08.024

Hulsey CD, Hollingsworth PR, Fordyce JA. (2010). Temporal diversification of Central American cichlids. BMC Evol Biol 10: 279. https://doi.org/10.1186\%2F1471-2148-10-279

Kodandaramaiah U (2011). Tectonic calibrations in molecular dating. Curr Zool 57: 116-124. https://doi.org/10.1093\%2Fczoolo\%2F57.1.116

Ilves KL, Torti D, López-Fernández H (2018). Exon-based phylogenomics strengthens the phylogeny of Neotropical cichlids and identifies remaining conflicting clades (Cichliformes: Cichlidae: Cichlinae). Mol Phylo Evol 118: 232-243.

https://doi.org/10.1016\%2Fj.ympev.2017.10.008

Iturralde-Vinent M, MacPhee RD (1999). Paleogeography of the Caribbean region: implications for Cenozoic biogeography. Bull Am Mus Nat Hist 238.

Iturralde-Vinent M (2004a). The conflicting paleontologic vs. stratigraphic record of the origin of the Caribbean. In: Bertolini C, Buffler R, Blickwede J (eds). The Gulf of Mexico and Caribbean region: Hidrocarbon habitats, basin formation and plate tectonics. Amer. Assoc. Petrol. Geol. Mem. pp. 75-88.

Iturralde-Vinent, M (2004b). Origen y evolución del Caribe y sus biotas marinas y terrestres. CD-ROM, La Habana. Centro Nacional de Información Geológica. ISBN: 959-7117-14-2

Iturralde-Vinent MA (2006a). Meso-Cenozoic Caribbean paleogeography: Implications for the historical biogeography of the region. Int Geol Rev 48:791-827.

https://doi.org/10.2747\%2F0020-6814.48.9.791

Peer) reviewing PDF | (2019:07:39927:2:1:NEW 26 Feb 2020) 
852 Iturralde-Vinent MA (2006b). El origen paleogeográfico de la biota de Guatemala. In: Cano EB 853 (ed). Biodiversidad de Guatemala Volumen I pp. 1-6. Publicado por Universidad del Valle de 854 Guatemala, Guatemala, pp 1-6.

855

856

857

Jordan BR, Sigurdsson H, Carey SN. Rogers R, Ehrenborg J (2006). Geochemical correlation of Caribbean Sea tephra layers with ignimbrites in Central America. In: Siebe C, Macías JL,

858

859 Aguirre-Díaz GJ (eds). Neogene-Quaternary continental margin volcanism: A perspective from

860

861

862

863

864

865

866

867

868 México: Geological Society of America Special Paper 402, Penrose Conference Series, pp 175208. https://doi.org/10.1130\%2F2006.2402\%2808\%29

\section{9}

870

871

872

873

874

875

876

877

878

879

880

881

882

883

884

885

886

887

888

889

890

891

892

893

894

895

896

897

Kirby MX, MacFadden BJ (2005). Was southern Central America an archipelago or a peninsula in the middle Miocene? A test using land-mammal body size. Palaeogeogr Palaeoclimatol Palaecol 228: 193-202. https://doi.org/10.1016\%2Fj.palaeo.2005.06.002

Kirby MX, Jones DS, MacFadden BJ (2008). Lower Miocene stratigraphy along the Panama Canal and its bearing on the Central American Peninsula. PLoS ONE 3: e2791. https://doi.org/10.1371\%2Fjournal.pone.0002791

Kullander SO (1983). A revision of the South American cichlid genus Cichlasoma (Teleostei, Cichlidae). Dissertation, Swedish Museum of Natural History.

López-Fernández H, Arbour JH, Winemiller KO, Honeycutt RL (2013). Testing for ancient adaptive radiations in Neotropical cichlid fishes. Evolution 67: 1321-1337.

https://doi.org/10.1111\%2Fevo.12038

Machado VN, Collins RA, Ota RP, Andrade MC, Farias IP, Hrbek T.(2018). One thousand DNA barcodes of piranhas and pacus reveal geographic structure and unrecognised diversity in the Amazon. Sci Rep 8: 8387. https://doi.org/10.1038\%2Fs41598-018-26550-X

Macphee RDE, Iturralde-Vinent M (2005). The Interpretation of Caribbean Paleogeography: Reply to Hedges. In: Alcover, JA, Bover P (eds): Proceedings of the International Symposium "Insular Vertebrate Evolution: the Palaeontological Approach”. Monografies de la Societat d'Història Natural de les Balears 12: 175-184.

Martin AP, Bermingham E (1998). Systematics and evolution of lower Central American cichlids inferred from analysis of cytochrome b gene sequences. Mol Phylo Evol 9: 192-203. https://doi.org/10.1006\%2Fmpev.1997.0461

Matamoros WA, McMahan CD, Chakrabarty P, Albert JS, Schaefer JF (2015). Derivation of the freshwater fish fauna of Central America revisited: Myers's hypothesis in the twenty first century. Cladistics 31: 177-188. https://doi.org/10.1111/cla.12081 
Mateos M (2005). Comparative phylogeography of livebearing fishes in the genera Poeciliopsis and Poecilia (Poeciliidae: Cyprinodontiformes) in central Mexico. J Biogeo 32: 775-780. https://doi.org/10.1111\%2Fj.1365-2699.2005.01236.x

903

904

905

Matschiner M, Musilová Z, Barth JM, Starostová Z, Salzburger W, Steel M, Bouckaert R. 906 (2017). Bayesian phylogenetic estimation of clade ages supports trans-Atlantic dispersal of

907

908

909

910

911

912

913

914

915

916

917

918

919

920

921

922

923

924

925

926

927

928

929

930

931

932

933

934

935

936

937

938

939

940

cichlid fishes. Syst Biol 66: 3-22. https://doi.org/10.1093\%2Fsysbio\%2Fsyw076

Matschiner M (2019). Gondwanan vicariance or trans-Atlantic dispersal of cichlid fishes: a

review of the molecular evidence. Hydrobiologia 832: 9-37. https://doi.org/10.1007\%2Fs10750$\underline{018-3686-9}$

Maturana RP, Brewer, BJ, Klaere, S, \& Bouckaert, R. (2018). Model selection and parameter inference in phylogenetics using Nested Sampling. Syst Biol 68: 219-233.

https://doi.org/10.1093\%2Fsysbio\%2Fsyy050

Miller, RR, Minckley, WL, \& Norris, SM (2005). Freshwater fishes of Mexico. University of Chicago Press.

Molina-Garza RS, van Hinsbergen DJ, Rogers RD, Ganerød M, Dekkers MJ (2012). The Padre Miguel Ignimbrite Suite, central Honduras: paleomagnetism, geochronology, and tectonic implications. Tectonophysics 574: 144-157. https://doi.org/10.1016\%2Fj.tecto.2012.08.013

Monaghan MT, Wild R, Elliot M, Fujisawa T, Balke M, Inward DJG, Lees DC, Ranaivosolo R, Eggleton P, BarracloughTG \& Vogler, AP. (2009) Accelerated species inventory on Madagascar using coalescent-based models of species delineation. Syst Biol 58: 298-311.

https://doi.org/10.1093\%2Fsysbio\%2Fsyp027

Mulcahy DG, Mendelson III JR (2000). Phylogeography and speciation of the morphologically variable, widespread species Bufo valliceps, based on molecular evidence from mtDNA. Mol Phylo Evol 17: 173-189. https://doi.org/10.1006\%2Fmpev.2000.0827

Musilová Z, Říčan O, Říčanová Š, Janšta P, Gahura O, \& Novák J. (2015). Phylogeny and historical biogeography of trans-Andean cichlid fishes (Teleostei: Cichlidae). Vertebr Zool 65: 333-350.

941

942 Myers GS, (1966). Derivation of the freshwater fish fauna of Central America. Copeia 1966:

943 766-773. https://doi.org/10.2307\%2F1441405 
944

945

946

947

948

949

950

951

952

953

954

955

956

957

958

959

960

961

962

963

964

965

966

967

968

969

970

971

972

973

974

975

976

977

978

979

980

981

982

983

984

985

986

Murray AM (2001). The fossil record and biogeography of the Cichlidae (Actinopterygii: Labroidei). Biol J Linn Soc 74: 517-532. https://doi.org/10.1111\%2Fj.1095-

$\underline{\text { 8312.2001.tb01409.x }}$

Nylander JAA (2004). MrModeltest v2.2. Program distributed by the author. Evolutionary Biology Centre, Uppsala University.

Obregón-Barboza H, Contreras-Balderas S, Lozano-Vilano ML. (1994). The fishes of northern and central Veracruz, Mexico. Hydrobiologia 286: 79-95.

https://doi.org/10.1007\%2Fbf00008499

Ogilvie, H. A., Bouckaert, R. R., \& Drummond, A. J. (2017). StarBEAST2 brings faster species tree inference and accurate estimates of substitution rates. Molecular biology and evolution 34: 2101-2114. https://doi.org/10.1093/molbev/msx126

Ornelas-García CP, Domínguez-Domínguez O, Doadrio I (2008). Evolutionary history of the fish genus Astyanax Baird \& Girard (1854)(Actinopterygii, Characidae) in Mesoamerica reveals multiple morphological homoplasies. BMC Evol Biol 8: 340. https://doi.org/10.1186\%2F14712148-8-340

Palacios M, Voelker G, Rodriguez LA, Mateos M, Tobler M (2016). Phylogenetic analyses of the subgenus Mollienesia (Poecilia, Poeciliidae, Teleostei) reveal taxonomic inconsistencies, cryptic biodiversity, and spatio-temporal aspects of diversification in Middle America. Mol Phylo Evol 103: 230-244. https://doi.org/10.1016\%2Fj.ympev.2016.07.025

Pérez-Higareda G, Navarro LD. (1980). The faunistic districts of the low plains of Veracruz, Mexico, based on reptilian and mammalian data. Bull Maryland Herpetol Soc 16: 54-69.

Pérez-Miranda F, Mejía O, Soto-Galera E, Espinosa-Pérez H, Piálek L, Říčan O (2018).

Phylogeny and species diversity of the genus Herichthys (Teleostei: Cichlidae). J Zool Syst Evol Res 56: 223-247. https://doi.org/10.1111\%2Fjzs.12197

Piálek L, Burress E, Dragová K, Almirón A, Casciotta J, Říčan O (2019a). Phylogenomics of pike cichlids (Cichlidae: Crenicichla) of the C. mandelburgeri species complex: rapid ecological speciation in the Iguazú River and high endemism in the Middle Paraná basin. Hydrobiologia: 832:355-375. https://doi.org/10.1007\%2Fs10750-018-3733-6 
987 Piálek L, Casciotta J, Almirón A, Říčan O. (2018b). A new pelagic predatory pike cichlid 988 (Teleostei: Cichlidae: Crenicichla) from the C. mandelburgeri species complex with parallel and 989 reticulate evolution. Hydrobiologia 832: 377-395. https://doi.org/10.1007\%2Fs10750-018-37549901

991

R Core Team. 2018. R: A language and environment for statistical computing.

Pons J, Barraclough TG, Gomez-Zurita J, Cardoso A, Duran DP, Hazell S, Kamoun S, Sumli, WD, Vogler,AP (2006). Sequence-based species delimitation for the DNA taxonomy of undescribed insects. Syst Biol, 55: 595-609. https://doi.org/10.1080\%2F10635150600852011

Powell J (2012) Accounting for uncertainty in species delineation during the analysis of environmental DNA sequence data. Methods Ecol Evol 3: 1-11.

https://doi.org/10.1111\%2Fj.2041-210x.2011.00122.x

Rambaut A, Drummond AJ, Xie D, Baele G, Suchard MA. (2018). Posterior summarisation in Bayesian phylogenetics using Tracer 1.7. Syst Biol 67: 991-904. https://doi.org/10.1093\%2Fsysbio\%2Fsyy032

Reznick DN, Furness AI, Meredith RW, Springer MS (2017). The origin and biogeographic diversification of fishes in the family Poeciliidae. PloS One 12: e0172546. https://doi.org/10.1371\%2Fjournal.pone.0172546

Řićan O, Piálek L, Zardoya R, Doadrio I, Zrzavý J (2013). Biogeography of the Mesoamerican Cichlidae (Teleostei: Heroini): colonization through the GAARlandia land bridge and early diversification. J Biogeo 40: 579-593. https://doi.org/10.1111\%2Fjbi.12023

1014 cichlid fishes (Teleostei: Cichlidae) with revised classification. Vert Zool 66: 3-102.

Rogers RD, Kárason H, van der Hilst RD (2002). Epeirogenic uplift above a detached slab in northern Central America. Geology 30: 1031-1034. https://doi.org/10.1130/00917613(2002)030<1031:EUAADS $>2.0 . \mathrm{CO} ; 2$

Rogers RD, Mann P, Emmet PA (2007). Tectonic terranes of the Chortis Block based on integration of regional aeromagnetic and geologic data. Boulder Geological Society of America, Special Paper 428: 65-88. https://doi.org/10.1130\%2F2007.2428\%2804\%29 
1028 Rosen DE (1975). A vicariance model of Caribbean biogeography. Systematic Biology, 24: 4311029 464. https://doi.org/10.2307\%2F2412905

1030

1031

1032

1033

1034

1035

1036

1037

1038

1039

1040

1041

1042

1043

1044

1045

1046

1047

1048

1049

1050

1051

1052

1053

1054

1055

1056

1057

1058

1059

1060

1061

1062

1063

1064

1065

1066

1067

1068

1069

1070

1071

1072

1073
Savage JM, Wake MH (2001). Reevaluation of the status of taxa of Central American caecilians (Amphibia: Gymnophiona), with comments on their origin and evolution. Copeia 2001: 52-64. https://doi.org/10.1643/0045-8511(2001)001[0052:ROTSOT]2.0.CO;2

Seehausen O (2015). Process and pattern in cichlid radiations-inferences for understanding unusually high rates of evolutionary diversification. New Phytol 207: 304-312. https://doi.org/10.1111\%2Fnph.13450

Suchard MA, Lemey P, Baele G, Ayres DL, Drummond AJ, Rambaut A (2018). Bayesian phylogenetic and phylodynamic data integration using BEAST 1.10. Virus Evol 4: vey016. https://doi.org/10.1093\%2Fve\%2Fvey016

Swofford DL (2003). Paup*: Phylogenetic analysis using parsimony (and other methods) 4.0. b10. Sinauer Associates, Sunderland. https://doi.org/10.1002/0471650129.dob0522.

Tagliacollo VA, Duke-Sylvester SM, Matamoros WA, Chakrabarty P, Albert JS (2017).

Coordinated dispersal and pre-isthmian assembly of the central american ichthyofauna. Syst Biol 66: 183-196. https://doi.org/10.1093\%2Fsysbio\%2Fsyv064

Villesen P (2007). FaBox: an online toolbox for fasta sequences. Mol Ecol Notes 7: 965-968. https://doi.org/10.1111\%2Fj.1471-8286.2007.01821.x

Vuataz L, Sartori M, Wagner A, Monaghan MT (2011). Toward a DNA taxonomy of Alpine Rhithrogena (Ephemeroptera: Heptageniidae) using a mixed Yule-coalescent analysis of mitochondrial and nuclear DNA. Plos One 6: e19728.

https://doi.org/10.1371\%2Fjournal.pone.0019728

Willis SC (2017). One species or four? Yes!... and, no. Or, arbitrary assignment of lineages to species obscures the diversification processes of Neotropical fishes. PloS One 12: e0172349. https://doi.org/10.1371\%2Fjournal.pone.0172349

Yu Y, Harris AJ, He X (2010). S-DIVA (Statistical Dispersal-Vicariance Analysis): a tool for inferring biogeographic histories. Mol Phylo Evol 56: 848-850.

https://doi.org/10.1016\%2Fj.ympev.2010.04.011 
1074 Zhang C, Zhang DX, Zhu T, Yang Z (2011). Evaluation of a Bayesian coalescent method of 1075 species delimitation. Syst Biol 60: 747-761. https://doi.org/10.1093\%2Fsysbio\%2Fsyr071

1076

1077

1078 Zhang J, Kapli P, Pavlidis P, Stamatakis A (2013). A general species delimitation method with 1079 applications to phylogenetic placements. Bioinformatics 29: 2869-2876.

1080 https://doi.org/10.1093\%2Fbioinformatics\%2Fbtt499

1081

1082

1083 


\section{Figure 1}

Study area

A: Study area location in eastern Mexico. B: Digital elevation model of the Gulf Coast of Mexico depicting the maximum sea level reached during the Miocene and Pliocene. Blue < $60 \mathrm{~m}$ a.s.l., Green $>60<1000 \mathrm{~m}$ a.s.I., Brown $>1000 \mathrm{~m}$ a.s.l. The black circles indicate the collection data of the specimens used in this study. C: The tested geograpical barrier of Punta del Morro (PdM) is indicated with a black arrow, the Herichthys ancestral area (haa) is showed in red and reconstructed extinction areas are shown with blue dagger sign and arrows.

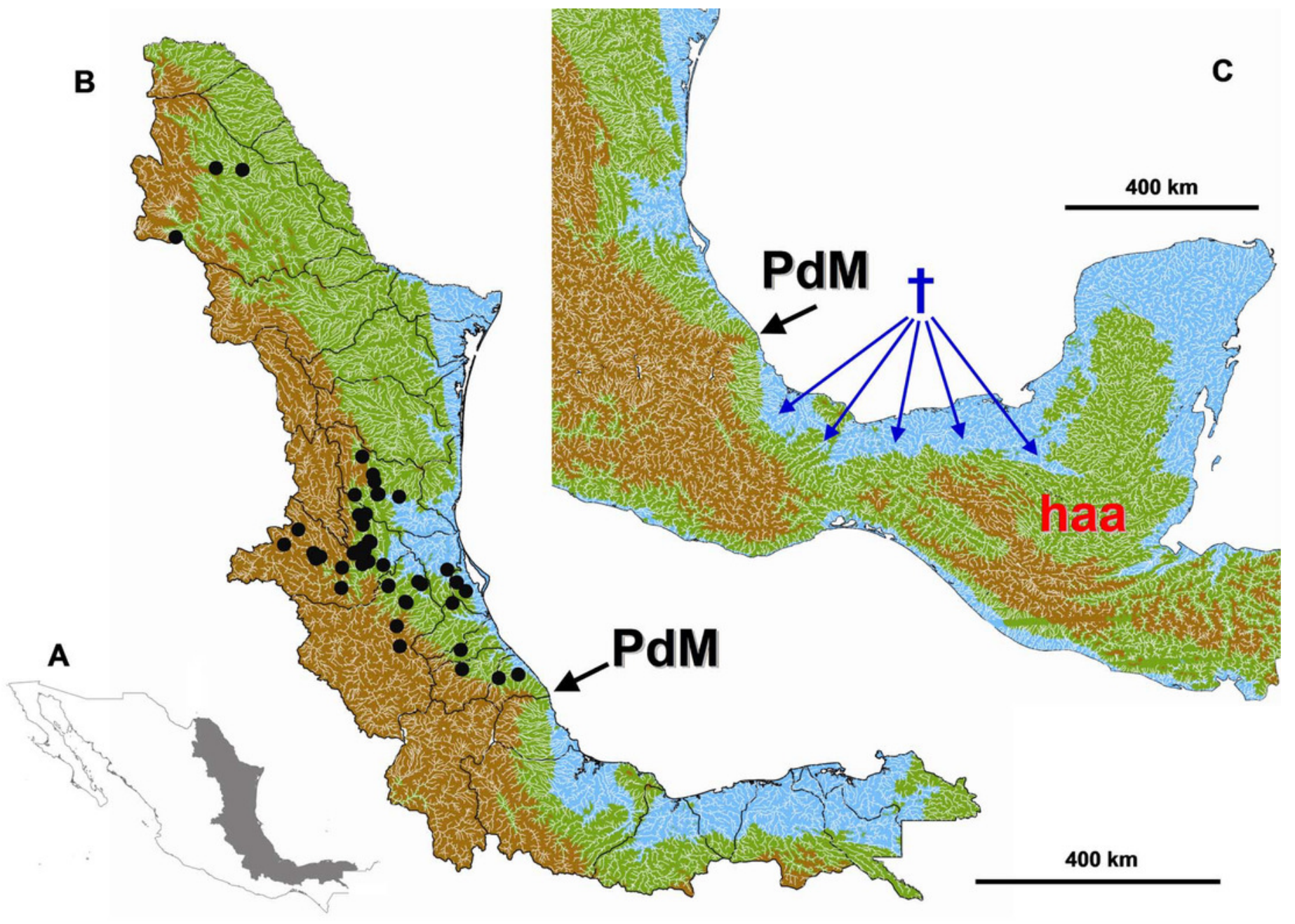




\section{Figure 2}

Phylogeny and biogeography of Herichthys

Phylogeny and biogeography of Herichthys based on the cytb haplotype dataset. The topology shown is a BEAST analysis. Species (haplotypes) are color-coded based on distribution areas (Herichthys endemic areas; shown in inset map). The endemic areas are optimized on the tree using S-DIVA analysis (ancestral areas at nodes shown by colored letters) which shows a nearly completely vicariant history of Herichthys. Vicariant events are shown by vertical two-sided arrows; those in black color show vicariant events that correspond to past high sea-level stands (see Fig. 3) and that separate lowland species where sea-level changes could have played a role. The three grey columns to the left of the tree show species delimitation based on bPTP, GMYC and Starbeast analyses. Agreement with present species classification is shown by intermediate grey color, over splitting is shown by dark grey color and failure to delimit recognized species is shown by light grey color. Black dots at nodes show node support above 0.95 in the BEAST analysis (shown only for putative species and deeper nodes; cf. with Figs. S1-S2). 


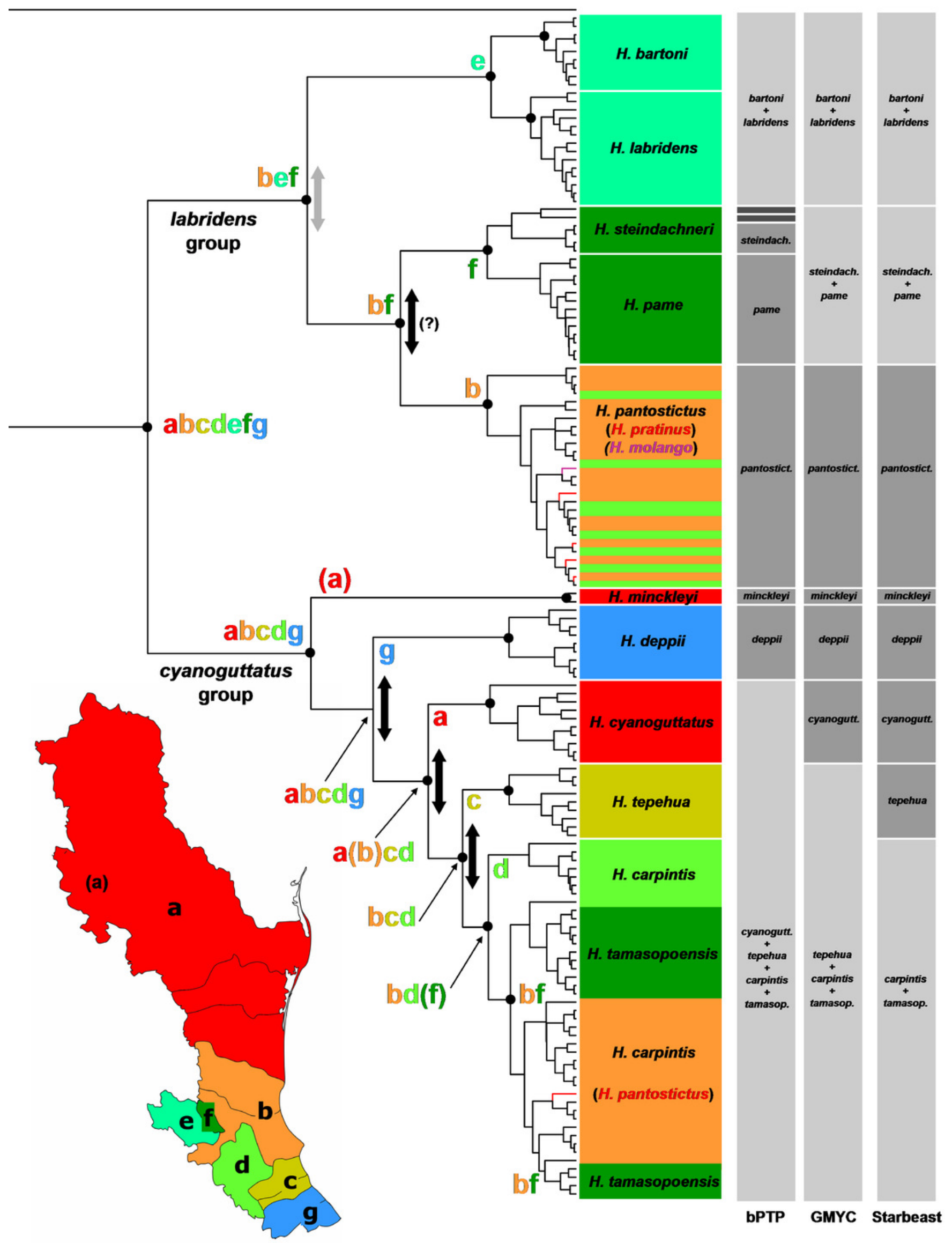




\section{Figure 3}

Dated phylogenies of Herichthys from Starbeast

Dated phylogenies of Herichthys from Starbeast based on the cytb dataset using the five calibrating analyses. Median dates for divergence of Herichthys from its closest sister-group (upper numbers; with 95\% HPD confidence intervals) and for the basal node of Herichthys (lower numbers) are shown. The colored columns show correspondence of Herichthys divergence (left column) and of Herichthys allopatric speciation events in the lowlands (right column) with high sea-levels. The divergence of Herichthys from its most closely related clades is thus a result of past high sea-level stands that occurred during the middle to late Miocene as shown by the good correspondence. 


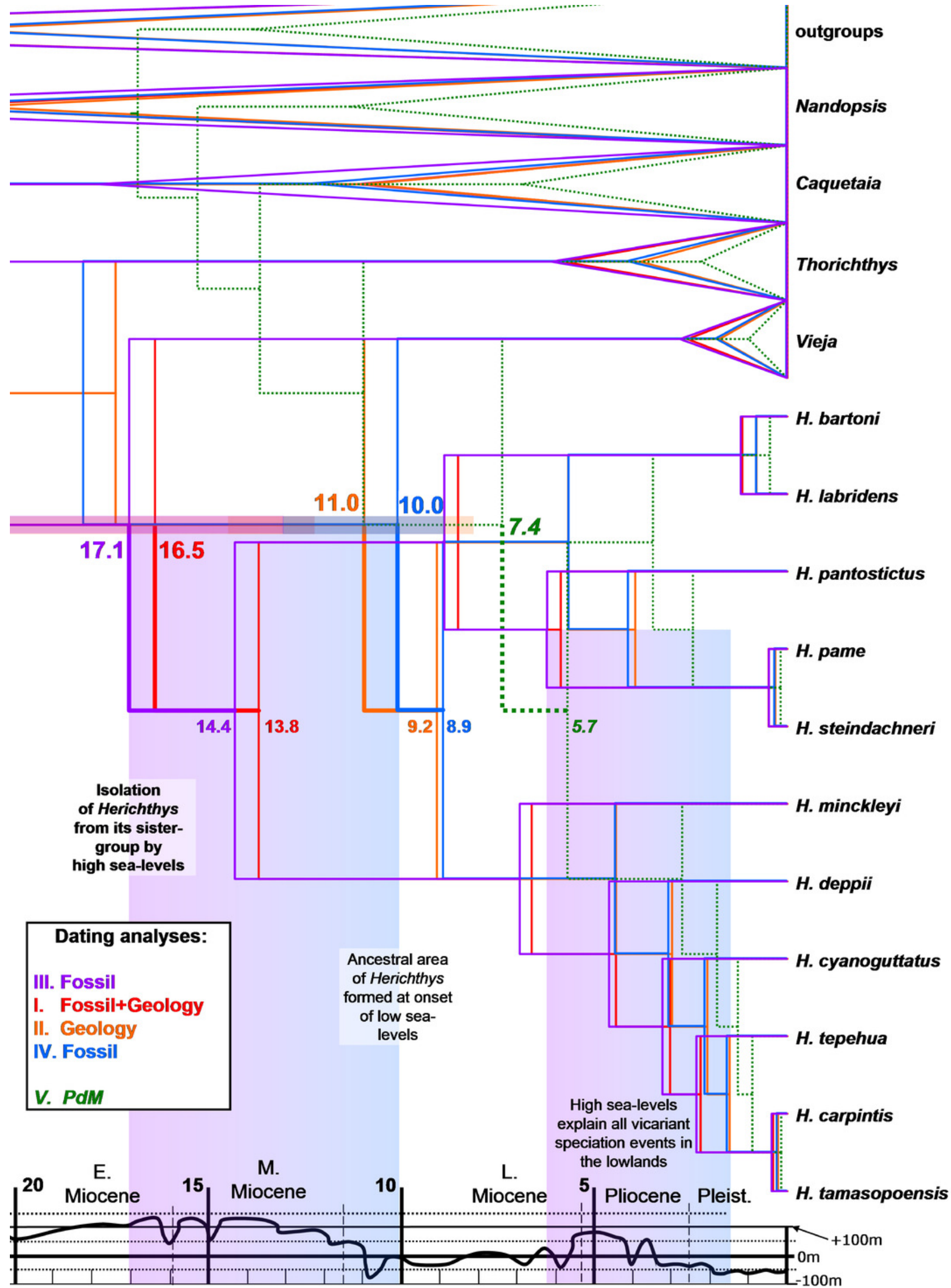




\section{Figure 4}

Biogeographical reconstruction of the Middle American

Biogeographical reconstruction of the Middle American cichlids based on the ddRAD phylogenetic hypothesis of Říčan et al. (2016). Reconstruction for nodes above the three Middle American clades is omitted from the figure. Reconstructed extinction events are shown by dagger signs that are color-coded in correspondence to the area where each extinction event occurred. Note that Herichthys is not separated from its closest relatives by a vicariant event but by a node with a large zone of reconstructed extinctions (shown in the upper inset map) following colonization (shown by the red to yellow arrow). For the same biogeographic analysis using the mtDNA-dominated multilocus dataset and for dating of the events including the identified extinctions in both analyses see Fig. S4 


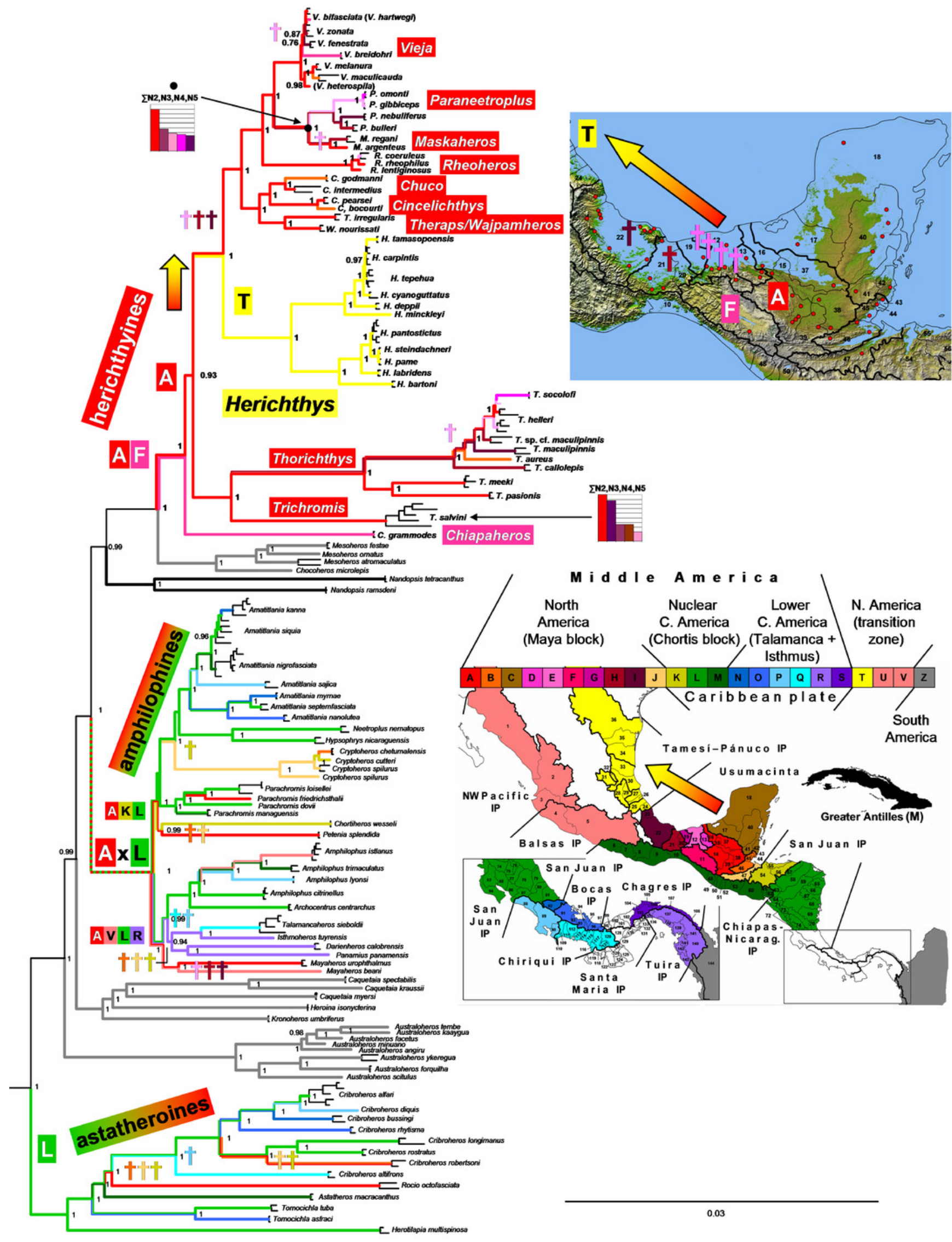

